\title{
Dihydroartemisinin exerts multiple effects in ameliorating CNS inflammation by enhancing AXL signaling in microglia from mouse model of multiple sclerosis
}

\section{Qingsen Ran}

china academy of chinese medical science

\section{Qi Li}

China Academy of Chinese Medical Sciences

\section{Li Liu}

China academy of chinese medical science

\section{Lidong Sun}

china academy of chinese medical science

\section{Qing Yang}

china academy of chinese medical science

\section{Yujie Li}

china academy of chinese medical science

\section{Ying Chen}

china academy of chinese medical science

\section{Xiaogang Weng}

china academy of chinese medical science

\section{Yajie Wang}

china academy of chinese medical science

\section{Weiyan Cai}

china academy of chinese medical science

Xiaoxin Zhu ( $\nabla$ zhuxx@icmm.ac.cn )

China Academy of Chinese Medical Sciences Institute of Chinese Materia Medica

\section{Research}

Keywords: Dihydroartemisinin, EAE, CNS inflammation, microglia, AXL

Posted Date: February 13th, 2020

DOI: https://doi.org/10.21203/rs.2.23348/v1 
License: (c) (i) This work is licensed under a Creative Commons Attribution 4.0 International License. Read Full License 


\section{Abstract}

Background: Dihydroartemisinin (DHA), a bioactive sesquiterpenoids originated from Artemisia annua L. , extensively applied in traditional medicine for the treatment of multiple autoimmune diseases. AXL, shown to dampen the immune response, reduce pro-inflammatory cytokine secretion, clear apoptotic cells and debris in Multiple sclerosis (MS), suggesting that it plays a role in disease pathogenesis. Thus, aiming to investigated whether DHA ameliorates experimental autoimmune encephalomyelitis (EAE) by modulating AXL signaling, we determined it both in vivo and vitro studies.

Methods: Firstly, female C57BL/6 mice were immunized with myelin oligodendrocyte glycoprotein MOG 35-55 peptide emulsified in complete Freund's adjuvant and injected with pertussis toxin on day 0 and 2 . Mice were monitored daily with DHA for clinical signs of disease and analyzed for pathology and ethology during the acute phase of disease. Moreover, functions of Immunological responses were assessed by flow cytometry and fluorescence microscope, chemokine were determined through ELISA and Transwell assay, proteins were monitored by Western blot and genes expression were explored by PCR.

Results: Results identified mice immunized with MOG35-55 had a significantly more severe acute phase of EAE than negative control mice. In contrast, DHA treated mice had slighter spinal cord lesions with less inflammatory cuffs, less demyelination, and slighter axonal damage than EAE mice. Furthermore, by using gait analysis, DHA obviously ameliorated clinical features in EAE mice. Strikingly, DHA reduced the chemotactic ability of microglia, promoted the differentiation of T cells into Treg cells and enhanced the phagocytic ability of microglia. Moreover, DHA up-regulated expression of AXL, SOCS3, and STAT1 phosphorylation. By contrast, no significant differences were noted in these responses above by using SGI7079, inhibitor of AXL. Furthermore, DHA up-regulated expression of AXL, SOCS3, and STAT1

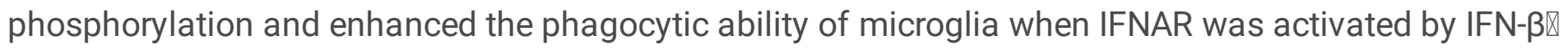
however, no significant differences were noted in these responses above by using Fludarabine, inhibitor of STAT1 phosphorylation.

Conclusions: Taken together, the present study demonstrated that DHA exerts multiple effects in ameliorating neuroinflammation process by enhancing $\mathrm{AXL}$ signaling that depending on modulating STAT1/SOCS3 axis in EAE, a mouse model of multiple sclerosis.

\section{Background}

Multiple Sclerosis, the most prevalent and an incurable chronic inflammatory disease of the central nervous system (CNS), inflicts more than 2 million people worldwide (at least 400,000 in the United States)[1]. Experimental autoimmune encephalomyelitis (EAE), the most commonly used in MS model[2], is characterized by abnormal inflammatory cells infiltrating into the central nervous system (CNS), a process that initiates the lesion formation and finally the demyelination of neuron axons[3, 4]. It is well 
established that inflammation in the CNS can block remyelination, but phagocytosis-led clearance of myelin debris can restart remyelination[5].

Microglia, resident CNS immune cells of monocyte lineage, play fundamental roles in maintaining homeostasis of CNS. Upon any CNS perturbation, they act to both resolve and exacerbate CNS disease[6]. Microglia/macrophages secret a battery of proinflammatory cytokines and present lots of antigen when aberrantly activated under pathologic environment, resulting in EAE and MS, especially in the white matter. In addition, they also exhibit regenerative properties through the phagocytizing myelin debris and secreting growth and neurotrophic factors[7]. We consider microglia to play a central role in: (1) the initiation of the acute inflammatory response within the CNS; (2) the clearance of damaged tissue [8]; the apparently irreversible tissue injury associated with the progressive disease phase[9].

Recent studies have revealed that TAM receptor protein tyrosine kinases, like TYRO3, AXL and MER, cellsurface transmembrane receptors, play pivotal roles in innate immunity. These receptors interact with multiple signaling molecules to regulate innate immune response, such as cell migration, survival, phagocytosis and efferocytosis[10]. The TAMs also function as rheostats to reduce the expression of proinflammatory molecules and prevent autoimmunity $[11,12]$. AXL, widely present in microglia, are known as regulators of multiple features of microglial physiology[10]. AXL has been shown to dampen the immune response, reduce pro-inflammatory cytokine secretion, clear apoptotic cells and debris, and maintain cell survival[13]. The deficiency of AXL also has a close relationship with many autoimmune diseases $[14,15]$. Thus, upregulation of AXL in MS lesions may help to protect resident CNS cells from apoptosis, dampen inappropriate activation of the immune response, and facilitate clearing myelin debris[12]. These data suggest that AXL serves as signal in multiple CNS cells during inflammation and repair.

Accumulating evidence showed that several types of chemokines, such as the potent immune cell chemoattractant chemokines RANTES, are upregulated in EAE and MS lesions, consequently leading to inflammation and demyelination[16]. Nevertheless, if AXL is inhibited, the chemotactic function of CCL5 is also repressed [17]. Apoptotic cells exert immunomodulatory effects on APCs. Bacterial and viral infections generate a large number of apoptotic cell corpses. Immune checkpoint plays a vital role as antigen (bacterial, viral, apoptotic cells) enter APCs and are cleared away by macrophages and DCs. Accumulating evidence suggests that PDL1 deficient mice become susceptible to EAE induction[18] and upregulated PDL1 expression in microglia could suppress Th1 cells via NO[19]. Furthermore, PDL1 can promote the differentiation of CD $4+T$ cells into Treg cells, a process that can inhibit neuroinflammation [20]. However, this homeostatic situation is also impaired in the TAM-deficient mice[17]. As resident apoptotic debris presents danger signals and autoantigens, TAM receptors and their ligands are required for the optimal phagocytosis of apoptotic cells in the mature immune and nervous systems. Furthermore, this receptor-ligand system is triggered by the "eat-me" signal phosphatidyl serine[12].

As the Toll-like receptors (TLRs) in dendritic cells were activated, it would trigger a rapid inflammatory response to pathogens. However, this response must be tightly regulated because unrestrained TLR 
signaling generates a chronic inflammatory milieu that often leads to autoimmunity[21]. Accumulating evidences showed that the TAM receptor tyrosine kinases-Tyro3, AXL, and Mer-broadly inhibit both TLR and TLR-induced cytokine receptor cascades[22]. Their importance notwithstanding, whether DHA is integrated with inflammation response remains to be elucidated.

Artemisinin is a sesquiterpene lactone isolated from the Chinese plant Artemisia annua L. [23]. Since the 1970s, artemisinin and its derivatives have been widely used in antimalaria drug to kill multidrug-resistant strains of malarial parasites[24]. Dihydroartemisinin (DHA) is an active metabolite shared by all artemisinin compounds (artemisinin, artesunate, artemether, and so on) and an important component in some drugs [25-27]. Apart from its prominent antimalaria effect, DHA is involved in a spectrum of cellular functions, including tumor cell growth, angiogenesis, and immune regulation[28]. In addition, DHA was initially demonstrated as an effective treatment option for SLE and is currently being assessed in a Chinese clinical trial. DHA and its derivatives can suppress delayed-type hypersensitivity response and collagen-induced arthritis, they were further reported as candidates for treating other autoimmune diseases [23]. These findings suggest that artemisinin derivatives are promising agents for modulating immune response and treating inflammatory diseases.

In this report, by using a murine model of EAE, we investigated how DHA treatment ameliorates CNS inflammation via up-regulating AXL that depends on STAT1/SOCS3 signaling pathway in microglia.

\section{Material And Methods}

\section{Animal experiments and Reagents}

Female C57BL/ 6 mice were obtained from institute of basic theory of Chinese medicine, China academy of Chinese medicine, and were used at 8 to 10 weeks of age. All mice were housed under specific pathogen-free conditions. All experiments were performed according to the institutional ethical guidelines on animal care and approved by the Institute Animal Care and Use Committee at BeiJing Institute of Materia Medica. SGI7079(MCE; HY-12964); Human IFN- $\beta$ (300-02BC-20); Fludarabine (MCE; B-0069); Mouse CCL5 ELISA kit (Proteintech, KE10017).

\section{Induction, treatment, and clinical evaluation of EAE}

C57BL/ 6 mice were immunized with MOG peptide ${ }_{35-55}(3 \mathrm{mg} / \mathrm{ml}$; Celtek Bioscience, Franklin, TN) emulsified in an equal volume of CFA composed of mycobacterium tuberculosis H37RA ( $10 \mathrm{mg} / \mathrm{ml}$; Difco Laboratories, Detroit, MI) in complete Freund's adjuvant (Sigma-Aldrich). Mice were anaesthetized with isoflurane and $120 \mu \mathrm{l}$ of emulsion was injected subcutaneously on each flank (200 $\mu \mathrm{l}$ total/ mouse) on day 0 . In addition, $500 \mu$ l of pertussis toxin $(1 \mu \mathrm{g} / \mathrm{ml}$; List Biological Laboratories, Campbell, CA) was injected into the tail vein on days 0 and 2. DHA (Chongqing Holley Wuling Mountain Pharmaceutical Company, purity $\geq 99 \%$ ) was dissolved in CMC-Na $0.5 \%$, which was used as the vehicle control. The mice were administered 2, 10 or 20 mg.kg-1 DHA per day or $1 \mathrm{mg} / \mathrm{kg}$ Methylprednisolone (Pfizer) per day. Clinical assessment of EAE was performed daily and mice were scored for disease according to the 
following criteria: 0 , no overt signs of disease; 1, limp tail or hind limb weakness but not both; 2, limp tail and hind limb weakness; 3, partial hind limb paralysis; 4, complete hind limb paralysis; 5, moribund state or dead.

\section{Cell Culture}

All cells were maintained in culture medium supplemented with 10\% fetal bovine serum (Gibco, USA) at $37^{\circ} \mathrm{C}$ in a humidified incubator (5\% CO2) (SANYO, JAPAN), with Jurkat T cells in RPMI-1640 medium and PC12 cells and BV 2 cells in DMEM medium.

\section{Histopathology}

To assess the degree of CNS inflammation and demyelination, immunized C57BL/6 mice treated with vehicle or SM934 were anesthetized by pentobarbital sodium and perfused by intracardiac injection of PBS containing 4\% paraformaldehyde. Paraffin embedded $5 \mathrm{~mm}$ sections of spinal cord were stained with H\&E and Luxol fast blue and then examined by light microscopy. Lumbar spinal cords were sliced into $1 \mathrm{~mm}$ sections. Tin sections were cut, stained with uranyl acetate and lead citrate and then analyzed under transmission electron microscope (Olympus, JAPAN). Briefly, inflammation was scored as follows: 0 , none; 1 , a few inflammatory cells; 2 , organization of perivascular infiltrates; 3 , increasing severity of perivascular cuffing with extension into adjacent tissue. Demyelination was scored as follows: 0 , none; 1 , rare foci; 2 , a few areas of demyelination; 3 , large (confluent) areas of demyelination.

\section{Gait analysis}

Gait assessment was carried out as described previously[29]. on the 24th day when the EAE mice were at the peak period by the automated computer-assisted method (Xin Hai Hua Yi Instrument Co., Beijing China). Data were collected and analyzed with Gait Analysis Lab software version 5.0. The equipment was located under natural light in a silent room. In brief, the system consists of an elevated $1.2 \mathrm{~m}$-long glass plate which is illuminated with a fluorescent light coming from the side and the fluorescent light is internally reflected in the glass allowing the paws to reflect light as they come into contact with the glass floor. A ceiling on top of the walkway creates a red background to produce the contour of the animal. A high-speed camera (100 frames) underneath the glass plate captures the images which are subsequently analyzed by the connected computer program. The video acquisition system is sealed with a PVC sheet to ensure a uniform dark environment to insure controlled lighting in the experiment. Prior to the first testing day, the animals were trained to traverse a glass walkway toward their home cage. On subsequent training days, three complete runs across the walkway were recorded by a camera positioned below. If an animal failed to complete a run within $5 \mathrm{~s}$, walked backwards, or reared during the run, the animal was given an additional re-run. Pixels below a light intensity of 20 units on a $0-255$ arbitrary scale were filtered out. Prints can be inspected individually and in combinations, and timing diagrams for paw placements are available.

\section{Isolation of spinal cord infiltrated mononuclear cell}


Spinal cord infiltrated mononuclear cells were isolated as described previously. The mice were anaesthetized with pentobarbital sodium and perfused with $20 \mathrm{ml}$ of cold PBS. The spinal cords were extruded by flushing the vertebral canal with PBS and rinsed in PBS. Tissues were forced through $70 \mathrm{mM}$ nylon cell strainers (BD Falcon), and then the spinal cord cell suspensions were incubated with collagenase IV $(2 \mathrm{mg} / \mathrm{ml})$ and DNasel $(100 \mu \mathrm{g} / \mathrm{ml})$ at $37^{\circ} \mathrm{C}$ for $30 \mathrm{~min}$, and passed again through $70 \mathrm{mM}$ nylon cell strainers to yield single-cell suspensions. CNS mononuclear cells were centrifuged $(500 \mathrm{~g})$ at room temperature for 20 min over discontinuous 30\%/ 70\% Percoll gradient (GE Healthcare). Then, lysed by TRIzol Reagent (Invitrogen) for qRT-PCR analyze and loading buffer for western blot analyze.

\section{Phagocytosis assay}

Phagocytosis assays was assessed as described previously[30], PC12 cells were induced to an apoptotic state by serum deprivation for 48 hours after being cultured. BV2 cells were plated at a cell density of $2 \times$ 105 cells. After induction of apoptosis, PC12 cells were harvested, stained with carboxy fluorescein diacetate succinimide ester (CFSE) and placed in contact with treated BV2 cells at a $3 / 1$ ratio for 2 hours so phagocytosis would occur. After coculturing, the supernatant was removed, and BV2 cells were harvested and stained with anti-F4/80-PE conjugated anti-mouse antibody diluted in PBS (1/200) for 30 minutes at $4^{\circ} \mathrm{C}$. After the incubation period, the cells taken to an flow cytometer and a total of 10000 events were acquired. Double-stained events were considered as phagocytosing BV2 cells, and percentage of such events was used to quantify phagocytosis. Then used the fluorescence microscope for qualitative phagocytosis analysis.

\section{Single cell extraction}

The brain and spinal cords were extruded by flushing the vertebral canal with PBS and rinsed in PBS. Tissues were forced through $40 \mathrm{mM}$ nylon cell strainers (BD Falcon), and then the spinal cord cell suspensions were incubated with collagenase $(1 \mathrm{mg} / \mathrm{ml})$ DNasel $(100 \mu \mathrm{g} / \mathrm{ml})$ at $37^{\circ} \mathrm{C}$ for $60 \mathrm{~min}$, and passed again through $40 \mathrm{mM}$ nylon cell strainers to yield single-cell suspensions. To ensure the cell viability more than $90 \%$ by using the trypan blue.

\section{0x Genomics single cell sequence}

The single cell sequencing was assessed as described previously [31] and implemented by oebiotech. Cells were processed using the $10 x$ Genomics Chromium Controller and the Chromium Single Cell $5^{\prime}$ Library \& Gel Bead Kit (PN 1000006) following the standard manufacturer's protocols (https://tinyurl.com/y96I7lns). Three technical replicates were run in parallel for each sample. In brief, between 14,000 and 21,000 live cells were loaded onto the Chromium controller in an effort to recover between 10,000 and 15,000 cells for library preparation and sequencing. Gel beads were prepared according to standard manufacturer's protocols. Oil partitions of single-cell + oligo coated gel beads (GEMs) were captured and reverse transcription was performed, resulting in CDNA tagged with a cell barcode and unique molecular index [32]. Next, GEMs were broken and cDNA was amplified and quantified using an Agilent Bioanalyzer High Sensitivity chip (Agilent Technologies). 


\section{Real-time PCR Assay}

Total RNA was isolated using Trizol reagent (Invitrogen), reverse transcribed, and polymerase chain reaction amplified using specific primers. three-Step Real-time PCR was performed with SYBR Green PCR Reagents (CWbio, China) was used with a total of 100 ng of RNA per reaction with PDL1, AXL, GAS6, RANTES, and ACTB (sequence was shown in supplementary data 1) primers according to the manufacturer's instructions. All results were normalized to ACTB as an internal control. The reactions were aliquoted in triplicate in an optical 96 well plate; RNase-free water was used as a blank. Reactions were run in the LightCycler $480 \otimes$, USA real-time PCR machine (Roche) with the following cycles: $95^{\circ} \mathrm{C}$ for 10 min to activate the DNA polymerase, followed by 45 cycles at $53^{\circ} \mathrm{C}$ for 15 seconds, and $72^{\circ} \mathrm{C}$ for 1 min. The real-time quantification was monitored directly by the StepOnePlus software and the comparative thresholds were identified for each gene with each RNA sample and calculated at the end of the measurements. After normalization of the, the fold change was determined as fold change $=2-$ $(\triangle \triangle C T)$ where $\Delta \Delta C T$ is defined as the normalized change in $C T$ between two groups. Statistics were performed on the normalized CT values. Premier Sequence: ACTB (Mus sapiens): Forward-5'GGCTGTATTCCCCTCCATCG3'; Reverse-5'-CCAGTTGGTAACAATGCCATGT-3'. AXL (Mus sapiens): Forward-5'-GGAACCCGTGACCCTACT-3'; Reverse-5'-GACTCCCTTGGCATTGTG-3'. GAS6 (Mus sapiens): Forward-5'-TACAGGCTCAACTACACCCG-3'; Reverse-5'-ACTGCCAGGACCACCAAC-3'. CCL5 (Mus sapiens): Forward-5'-ACCACTCCCTGCTGCTTT-3'; Reverse-5'-ACACTTGGCGGTTCCTTC-3'. PDL1 (Mus sapiens): Forward-5'-GTGGTGCGGACTACAAGC-3'; Reverse-5'-CAGGCAGTTCTGGGATGA-3'.

\section{Protein extraction and Western Blot}

Proteins were extracted from the lungs of all subjects and lysed with Loading Buffer. Whole-cell extracts were prepared and protein concentrations were measured using a BCA assay kit. Total proteins were separated by sodium dodecyl sulfate-polyacrylamide gel electrophoresis (SDS-PAGE) and blotted to polyvinylidene fluoride (PVDF) membranes (Merck Millipore, IPVH00010) via electrophoretic transfer. Membranes were blocked for $2 \mathrm{~h}$ at room temperature with $5 \%$ powdered skimmed milk and exposed to primary antibodies overnight at $4^{\circ} \mathrm{C}$. Horseradish peroxidase-conjugated antibody against mouse and antibody against rabbit were used as secondary antibodies. After extensive washing, protein was visualized on X-ray film following an ECL plus assay kit (Thermo Scientific) and analyzed by Image J software.

\section{Flow cytometry}

For cell surface staining, cells first blocked with $3 \%$ FBS for $15 \mathrm{~min}$ in room temperature and then were stained with antibodies anti-PDL1-FITC (Proteintec, USA) for $1 \mathrm{~h} 4{ }^{\circ} \mathrm{C}$ to analyze whether DHA influence the PDL1 expression on microglia and macrophages. For intracellular staining, cells were first used Triton100 for $15 \mathrm{~min}$ in room temperature, and then used anti-FOXP3-FITC(Proteintec, USA) for $1 \mathrm{~h} 4{ }^{\circ} \mathrm{C}$ to analyze whether DHA promote T cell differentiation into Treg cells. Finally, all cells were sorted on the BECKMAN Flow Cytometer. 


\section{Trans-well assay}

A trans-well ( $8 \mu \mathrm{m}$ pore size; Falcon, USA) assay was used to further analyze chemotaxis ability of BV2 cells according to the manufacturer's instructions. BV2 cells at the density of $5 \times 10^{4} / \mathrm{mL}$ were placed in the upper chambers in $0.3 \mathrm{ml} 5 \%$ serum media, and the lower chambers were added with $0.6 \mathrm{~mL}$ LPS 50 $\mathrm{ng} / \mathrm{mL}, 1 \mu \mathrm{M}$ DHA+LPS $50 \mathrm{ng} / \mathrm{mL}, 4 \mu \mathrm{M}$ DHA+ LPS $50 \mathrm{ng} / \mathrm{mL}$, or $10 \%$ serum DMEM as negative control. Cells were allowed to transmigrate into the lower chamber following incubation for $12 \mathrm{~h}$ at $37^{\circ} \mathrm{C}$; nonmigrating cells on the upper chamber surface were removed. The membranes were fixed with $4 \%$ paraformaldehyde in PBS for 30 min and stained with crystal violet in PBS for $15 \mathrm{~min}$. The representative images (magnification, $\times 200$ ) were randomly taken by an inverted microscope. Each experimental group was repeated three times.

\section{ELISA for CCL5 detection}

Serum and cerebrospinal fluid were taken at the day 26 and culture supernatants from BV2 cells were evaluated using ELISA kit (all from proteintech, USA) according to the manufacturer's instructions.

\section{Statistical analysis}

Data were analyzed using GraphPad Prism 7 sofware (GraphPad, La Jolla, CA, USA), and are presented as the mean \pm SEM. Significant differences in comparing multiple groups, data were analyzed by one-way ANOVA test. All other statistical comparisons were done using nonparametric statistical tests. Differences with $p$ values of less than 0.05 were considered significant.

\section{Results}

\section{DHA treatment inhibited the development of EAE in MOG-immunized C57BL/6 mice}

To investigate the protective effects of DHA against $E A E$, we immunized female C57BL/6 mice with MOG35-55 peptide emulsified with CFA, followed by oral administration of DHA $(2,10,20 \mathrm{mg} / \mathrm{kg})$, $\operatorname{MET}(1 \mathrm{mg} / \mathrm{kg}$ ) or vehicle (daily from post-immunization Day 7). All mice $(100 \%)$ in the vehicle treated group developed severe EAE at Day 15 to 18. In contrast, less than $60 \%$ of the mice treated with DHA showed mild signs. Besides, the mice treated with DHA exhibited significant reduction in the severity of EAE. On Day 21, when EAE clinical score reached the peak, the mean score of vehicle group exceeded that of DHA (10mg/kg)-treated group by two folds (Figure 1A). DHA treatment also markedly prevented the loss of body weight in EAE mice (Figure 1B).

Histological analysis was performed using spinal cord and brain tissue sectioned from negative control, vehicle, MET and DHA treated mice. Typical inflammation (H\&E stain) and demyelination (Luxol Fast Blue) were observed in vehicle treated mice, and DHA treatment remarkably attenuated CNS inflammation and demyelination (Figure $1 \mathrm{CD}$ and $\mathrm{E}$ ). These results suggested that DHA reduced clinical severity and inhibited inflammatory responses in EAE mice. 
Transmission electron microscope analysis on spinal cord showed abundant remyelinated axons in negative control mice; conversely, vehicle treated mice showed swollen axons containing autophagosomes, auto-phagolysosomes, and multivesicular bodies, fewer myelinated axons, glial aggregates and abnormal myelin. Myelinated axons were reappeared and the abnormal myelin almost disappeared after DHA treatment. In conclusion, DHA could ameliorate EAE in MOG-immunized C57BL/6 mice (Figure 1F).

Gait analysis results of C57BL/6 mice subjected to EAE were shown in Figure 1G, H, I, J, K. DHA treatment could increase the walk speed, Lh-Rh Pressure, Lh-Rh support time, Lh-Rh Print area, and ameliorate Body Rotation Average, compared with the vehicle treated group. In conclusion, DHA treatment could inhibited the development of EAE in MOG-immunized C57BL/6 mice.

\section{Macrophages and microglia are disease-responsive cells in EAE mice}

Microglia are the resident macrophages of the CNS. They are classified as mononuclear phagocytes and are uniquely positioned in the parenchyma of the CNS. Recent progress in understanding the autoimmune neuroinflammatory disease multiple sclerosis and its animal model experimental autoimmune encephalomyelitis suggests major roles for microglia in the disease. In MS and EAE, microglia induce different effector functions that can be both neuroprotective and detrimental. Currently, it is believed that the initial response of microglia is beneficial, aiming to resolve the insult, but that chronic activation of microglia contributes to neurodegeneration[33]. To determine whether macrophages and microglia play significant role in disease progression of EAE. By using the 10X Genomics single-cell sequencing, we analyzed the disease-responsive cells. Firstly, the t-SNE projection of scRNA-seq data showed 15 EAE-responsive clusters (Figure 2A, B). Among the 15 clusters, macrophages and microglia constituted the two largest. The most weighted genes in each principal component were shown with graph-based clusters.

\section{DHA treatment promoted the differentiation of T cells into Treg cells by enhancing PDL1 expression in macrophages and microglia}

Costimulatory and coinhibitory accessory molecules play a key role in modulating immune responses to pathogens or autoantigens. Furthermore, disruption of costimulatory signals or augmentation of coinhibitory signals are considered therapeutically attractive approaches for modulating $T$ cell activity in autoimmune and inflammatory diseases[34, 35]. As coinhibitory accessory molecule, PD-L1 expression is suggested to be an important marker of "primed" macrophages and promote the differentiation of T cells into Treg cells[36]. To examine the expression of PD-L1, we first used Raw264.7 cells and peritoneal macrophages by using RT-PCR assay. PDL1 is lowly expressed in the cells in a resting state. Therefore, we used LPS $(50 \mathrm{ng} / \mathrm{ml})$ to activate cells. As shown in Figure $2 \mathrm{C}, \mathrm{DHA}(4 \mu \mathrm{M})$ obviously increased the expression of PDL1, compared with LPS $(50 \mathrm{ng} / \mathrm{ml})$ in the two macrophages. For further detection of surface expression of PDL1 in macrophages and microglia, the results showed that DHA $(4 \mu \mathrm{M})$ could not only significantly up-regulate the expression of PDL1 in Raw264.7 cells (Figure 2D) and peritoneal macrophages (Figure 2E), but also in BV2 cells(Figure 2F), compared with LPS (50ng/ml). To further 
detect whether DHA directly influences the cellular activities of T cells, we established a co-culture model of BV2-Jurkat T cells. Results in Figure $2 \mathrm{G}$ showed that DHA $(1,4 \mu \mathrm{M})$ significantly enhanced the proliferation of Treg cells (CD4+Foxp3+), compared with LPS $(50 \mathrm{ng} / \mathrm{ml})$ group. These results showed that DHA treatment suppressed antigen presentation by up-regulating PDL1 expression in macrophages and microglia and promoted the differentiation of $T$ cells into Treg cells.

\section{DHA treatment reduced the chemotactic ability of microglia by regulating CCL5}

Previous research showed that CCL5 and their receptor CCR5 play crucial roles in the trafficking of encephalitogenic T cells and the inflammatory responses in the CNS [37]. In EAE mice, the expression of chemokines and the distribution of leukocytes infiltrating into the CNS show a tight correlation with the development of disease[38]. By using the 10X Genomics single-cell sequencing, we analyzed the diseaseresponsive genes. CNV analysis showed that CCL5 is mainly expressed in macrophages and microglia (Figure3A, B red, cells with detected CNVs; gray, cells with undetected CNVs). Thus, to determine the veracity of the $10 X$ Genomics single-cell analysis, we firstly analyzed the MNCS separated from all groups of mice by using the qRT-PCR assay. As shown in Figure3 C, DHA treatment could down-regulate the gene expression of CCL5, compared with the vehicle control group. we also examined the concentration of CCL5 by using the ELISA assay. As shown in Figure 3D, E, the concentration of CCL5 in the serum of EAE mice was significantly up-regulated, compared with the NC group, and down-regulated after DHA and MET treatment. Furthermore, we also detected the concentration of CCL5 in the cerebrospinal fluid (CSF). Amazingly, the concentration of CCL5 in CSF in the EAE group was about 2-fold higher than that in DHA treatment group, both being dose-dependent. Functionally, to determine the counts of chemotactic microglia, we used LPS and DHA to induce the production of CCL5 for $12 \mathrm{~h}$. Next, the supernatant was collected for the detection of CCL 5 concentration by using ELISA assay. The results in Figure $3 \mathrm{~F}$ showed that DHA treatment could obviously reduce LPS-increased concentration of CCL5. Furthermore, trans-well assay showed that DHA $(1,4 \mu \mathrm{M})$ treatment could reduce LPS $(50 \mathrm{ng} / \mathrm{ml})$ increased chemotactic ability of BV2 cells (Figure $3 G$ ). Together, these results indicated that DHA treatment reduced the chemotactic ability of microglia by regulating CCL5.

\section{DHA treatment enhanced the phagocytic ability of microglia via up-regulating AXL}

TAM receptors interact with multiple signaling molecules to regulate cell migration, survival, phagocytosis and clearance of metabolic products and cell debris called efferocytosis. AXL, referred to as one of the TAM family of receptor tyrosine kinases, is expressed in cells of the brain, monocytes/macrophages, and microglia. AXL is expressed by microglia and play a role in eliminating apoptotic newborn neurons in the subventricular zone [10]. By using the $10 X$ Genomics single-cell sequencing, we analyzed the diseaseresponsive genes. CNV analysis showed that $A X L$ is mainly expressed in macrophages and microglia (Figure4A, B red, cells with detected CNVs; gray, cells with undetected CNVs). Furthermore, to determine the veracity of the $10 X$ Genomics single-cell analysis, we firstly analyzed the MNCS separated from all groups of mice by using the qRT-PCR assay. As shown in Figure4 C, DHA treatment could up-regulate the expression of $A X L$ compared with the vehicle control group. Moreover, GAS6, ligand for AXL, showed no 
different expressions among each group. The protein expression of $A X L$ was further detected by Western

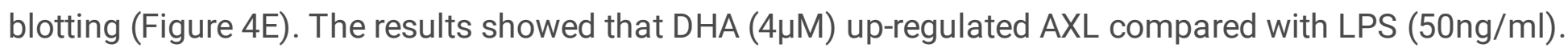
Microglia, APCs in CNS, can engulf apoptotic cells and myelin debris in the CNS[39]. To further determine the phagocytic ability of BV2 cells, we firstly induced the apoptosis PC12 cells using 5-F. AV-PI data in Figure $4 \mathrm{~F}$ showed the apoptotic rate of PC12 cells exceeded that of NC group by $>70 \%$. Then, by utilizing fluorescence microscope and flow cytometry assay, we qualitatively and quantitatively analyzed the phagocytic ability of BV2 cells. As shown in Figure 4G, H DHA treatment could obviously recover the phagocytic function of microglia reduced by LPS. Compared with LPS (50 ng/kg) group, the count and percentage of PC12 cells phagocytized by BV2 cells were both significantly increased by DHA $(1,4 \mu \mathrm{M})$ treatment. These in vitro results further demonstrated that LPS induction could weaken the phagocytosis of microglia and that these changes could be reversed by DHA treatment.

\section{DHA treatment suppressed CNS inflammatory response via up-regulating AXL through STAT1/SOCS3 pathway}

Some researchers have found that the phosphorylation and activation of STAT1 and SOCS3 transcription are initiated by AXL up-regulation that reduces the activation of Toll-like receptors (TLRs) and the consequent expression of proinflammatory molecules[10]. As shown in Figure 5, we testified whether DHA inhibits CNS inflammatory response via up-regulating AXL through STAT1/SOCS3 pathway. By using western blotting, we firstly detected the expression of Phospho-AXL and total AXL in BV2 cells. When treated with DHA $(4 \mu \mathrm{M})$, the expression of total AXL and Phospho-AXL were all obviously upregulated, compared with those in LPS $(50 \mathrm{ng} / \mathrm{ml})$ group. And then, we also examined the phosphorylation of STAT1 1 and the expression of SOCS3 in BV2 cells. The expression of Phospho-STAT1 and SOCS3 was up-regulated by DHA, then down-regulated by LPS.

\section{AXL is the potential target of DHA in CNS inflammatory niche}

It has been indicated that DHA could ameliorate CNS inflammation by reducing the chemotactic ability of microglia, promoting the differentiation of $T$ cells into Treg cells, and enhancing the phagocytic ability of microglia in above results. Furthermore, accumulating evidence said that defects in TAM signaling disrupt cellular processes that regulate homeostasis, phagocytosis, and inflammation and can result in autoimmune disease. Defects in TAM signaling would also lead to multiple sclerosis (MS) as well as mouse models of these diseases. Upon Gas6 stimulation, SGI7079 treatment can inhibit the phosphorylation of AXL at Tyr 702. We determined whether AXL is the potential target of DHA in CNS inflammatory niche. As shown in Figure 6, BV2 cells unchallenged with AXL showed normal physiology. In contrast, After the treatment of SGI7079, we found that the phagocytic ability of BV2 cells, the differentiation of Jurkat T cells co-cultured with BV2 cells, and the chemotactic ability of BV2 cells disappeared, and these abilities showed no difference among DHA treatment, LPS group and NC group $(P>0.05)$. Thus, these data indicated that $A X L$ would be a potential target in treating EAE.

Furthermore, we also used SGI7079 to block the activation of AXL. As shown in Figure 6G, DHA did not change the expression of Phospho-AXL, Phospho-STAT1 and SOCS3, but up-regulated the expression of 
total AXL. These results indicated that DHA could up-regulate the expression of total AXL to inhibit CNS inflammatory response via STAT1/SOCS3 pathway.

\section{DHA inhibition of inflammation in CNS is dependent on the presence of the type I IFN receptor}

In response to pathogens, host defenses was activated by TLRS which responsible for local inflammation. Previous studies have shown that TAM receptor established its role as a pleiotropic inhibitor of both TLR- and cytokine-driven immune responses. Apparently, TAM inhibition of inflammation is transduced through an essential stimulator of inflammation-the type I interferon receptor (IFNAR)and its associated transcription factor STAT1. TLR induction of IFNAR-STAT1 signaling upregulates the TAM system, which in turn usurps the IFNAR-STAT1 cassette to induce the cytokine and TLR suppressors SOCS1 and SOCS3[22]. As shown in Figure 7A, BV2 cells unchallenged with IFB- $\beta$ showed normal physiology. In contrast, After the treatment of FLU, inhibitor of STAT1, we found that the phagocytic ability of BV2 cells disappeared, and these abilities showed no difference among DHA treatment. Moreover, we also used FLU to block the activation of STAT1, DHA did not change the expression of AXL, Phospho-AXL, Phospho-STAT1 and SOCS3. These results indicated that DHA inhibition of inflammation in CNS is dependent on the presence of the type I IFN receptor.

\section{Discussion}

Multiple sclerotic lesions, most as foci of demyelination, inflammation, and glial reaction in the white matter, can appear in all parts of the CNS[1]. In this study, DHA significantly decreased the inflammatory infiltration into the CNS and the demyelination, thus halting the development of EAE.

In another part of our work, by using the 10X single cell sequencing, we identified that DHA treatment functions through macrophages and microglia and that AXL and CCL5 respond to both types of cells. In this study, we identified that AXL-regulated antigen presentation, chemotaxis of inflammatory cells and phagocytosis of apoptotic cells were all decreased and this decrease showed no significance between DHA treatment and LPS group. Furthermore, we also determined DHA inhibited CNS inflammation via upregulating AXL through STAT1/SOCS3 pathway in BV2 cells. Taken together, these in vivo and vitro study demonstrated that AXL may be a key target in treating EAE by DHA. We also indicated that DHA is integrated with inflammation response in CNS, which dependent on the presence of the type IIFN receptor.

Artemisinin and its derivatives, such as artesunate and dihydroartemisinin, have been reported to have immunity-regulating effects $[23,40]$. However, the underlying mechanism remains poorly defined. In this study, we found that DHA can be used as an Ag-specific/-nonspecific immunosuppressant with few side effects by inhibiting CNS inflammation at the onset of the EAE. Some research found that DHA suppressed EAE by regulating $T$ cell differentiation[28], but more interestingly, our research revealed that DHA also regulated microglia or macrophages. These findings suggest that artemisinin derivatives constitute a new class of immune regulatory agents that suppress immune function. 
In this report, microglia actively participate in almost all MS processes[9]. Microglia serve as the major immunocompetent element and frontline cells in the damaged CNS, therefore, modulating microglia function can be a therapeutic strategy in coping with CNS inflammation and inflammation-induced demyelination[33]. However, activated microglia would produce a large amount of pro-inflammatory cytokines[41] and chemokines, which mobilize more immune cells to infiltrate into the CNS[42]. Thus, this knowledge makes it possible to pinpoint potential microglial-related targets in MS that can manipulate and restore microglial functions[33]. In addition, microglia, as a type of biomarker to monitor disease progression in MS, could be used a target in DHA treatment of EAE.

To further investigate the mechanism of microglia-mediated immunoregulation, we investigated PDL1, as a member of the immune checkpoint molecule family, is expressed on the surface of microglia[19]. The PD-L1/PD1 pathway can deliver inhibitory signals that regulate both central and peripheral immune tolerance[43]. Accumulating evidence suggests that the inhibitory ability of microglia is associated with the production of NO through PD-L1/PD1 pathway. It is of interest to evaluate the relationship between PD-L1 and NO, and the role of DHA in the interaction between APC and T cells.

Although our findings suggest that DHA may be beneficial in treating inflammatory disease, some studies showed that immune suppressants may bring with detrimental effect in clearing malaria. Malaria pathogens can be effectively cleared by DHA; however, DHA-resistant strains may emerge and cause the recrudescence of malaria[28]. In contrast, Treg function can be enhanced by DHA, which may avoid malaria-induced immune dysfunction. It has been shown that enhanced Treg function paradoxically prevented experimental cerebral malaria[44]. Therefore, how DHA affects immune function is a critical question to be resolved before developing new malaria treatments.

Accumulating evidence indicates that AXL plays a role during the switch from inflammatory activation to inflammatory feedback inhibition. When pathogens activate Toll-like receptor (TLR) signaling pathways, cytokine receptor signaling pathways is activated to over-produce pro-inflammatory cytokines, which are then greatly amplified in a feed-forward loop through cytokine signaling pathway. Consequently, the expression of the TAM receptor AXL is up-regulated. AXL coordinates with IFNAR and phospho-STAT1 to induce the expression of SOCS3, which broadly inhibits both TLR and cytokine receptor cascades. In this loop, IFN secretion could be seen as a signal source, AXL expression as a marker, and STAT1/SOCS3 induction as a functional foothold in self-limiting inflammatory response. Mechanically, we found that AXL was closely related to the activation of IFNAR, because when the anti-inflammatory function was activated, a clear co-regulation initiated to form a molecular complex. In this complex, both IFNAR and AXL appear in the production of inflammatory self-limiting signals[11, 22].

Taken together, our findings indicate that $A X L$ is a potential therapeutic target for MS by DHA. DHA could up-regulate $A X L$ and $A X L$ cooperates with IFNAR, to inhibit the CNS inflammation. How DHA influences the expression of AXL needs further investigation.

\section{Conclusions}


Taken together, These data support the conclusion that Dihydroartemisinin ameliorated CNS inflammation by enhancing $A X L$ signaling in microglia from mouse model of multiple sclerosis. we highlighted the central role of $A X L$ in controlling the progression of EAE. We also for the first time revealed that, by increasing AXL expression, DHA has a potential in reducing the chemotactic ability of microglia, promoting the differentiation of $T$ cells into Treg cells and enhancing the phagocytic ability of microglia, thus efficiently ameliorates EAE. Furthermore, we also highlighted the efficiency of DHA was acted as "NO INFLAMMATION, NO INHIBITION".

\section{Abbreviations}

CNS: central nervous system

MS: Multiple Sclerosis

EAE: Experimental Autoimmune Encephalomyelitis

APCs: antigen presentation cells

AXL: Anexelekto

PDL1: Programmed cell death ligand 1

STAT1: signal transducer and activator of transcription 1

SOCS3: suppressor of cytokine signaling 3

GAS6: growth arrest specific gene 6

CCL5(RANTES): regulated upon activation normal T cell expressed and secreted factor

\section{Declarations}

\section{Ethics Statement}

All animal experiments were approved by the local Laboratory Animal Ethics

Committee of the Institute of basic theory of traditional Chinese medicine, of the China Academy of Chinese Medical Sciences (license number SCXK 2016-0021) and performed in accordance with the guidelines for the care and use of laboratory animals.

\section{Competing interests}


The funding agency had no role in study design, data collection and analysis, decision to publish or preparation of the manuscript. The authors have no financial or non-financial competing interests to declare.

\section{Author contribution}

Qingsen Ran and Qi Li participated in the manuscript writing and experimental design and performed the experiments. Lidong Sun and Li Liu participated in performing parts of the experiments. Qing Yang, Yujie $\mathrm{Li}$, Ying Chen, Xiaogang Weng, Yajie Wang, Weiyan Cai participated in the manuscript writing, manuscript editing and data analysis. Xiaoxin, Zhu participated in the manuscript writing, experimental design and data analysis. All authors have read and approved the manuscript.

\section{Funding}

This work was supported by grants from National High Technology Research and Development Program of China (2017ZX09101002-002-002); Institute of traditional Chinese medicine internal project- the research on reevaluating traditional Chinese medicine based on antibiotic substitution (NO. Z201701903); "the Belt and Road" cooperation project of China academy of traditional Chinese medicine (NO. GH201914); The General Programs of the National Natural Science Foundation of China (8157141621); Special training program for outstanding young scientific and technological talents of China academy of Chinese Medical Science (ZZ13-YQ-044); Independent topic selection project China academy of Chinese Medical Science (ZXKT17010); China academy of traditional Chinese medicine internal project-Construction of China-European research center for traditional Chinese medicine and natural products (NO. GH2017-01).

\section{Consent for Publication}

Not applicable

\section{Availability of supporting data}

The datasets used or analysed during the current study are available from the corresponding author on reasonable request.

\section{Acknowledgements}

Grateful acknowledgement is made to my supervisor professor Xiaoxin Zhu who gave me considerable help by means of suggestion, comments and criticism. His encouragement and unwavering support have sustained me through frustration and depression. Without his pushing me ahead, the completion of this thesis would be impossible. In addition, I deeply appreciate the contribution to this thesis made in various ways by my friends and classmates.

\section{References}


1. Reich DS, Lucchinetti CF, Calabresi PA: Multiple Sclerosis. N Engl J Med 2018, 378:169-180.

2. Bittner S, Afzali AM, Wiendl H, Meuth SG: Myelin oligodendrocyte glycoprotein (MOG35-55) induced experimental autoimmune encephalomyelitis (EAE) in C57BL/6 mice. J Vis Exp 2014.

3. Constantinescu CS, Farooqi N, O'Brien K, Gran B: Experimental autoimmune encephalomyelitis (EAE) as a model for multiple sclerosis (MS). British Journal of Pharmacology 2011, 164:1079-1106.

4. Vainchtein ID, Vinet J, Brouwer N, Brendecke S, Biagini G, Biber K, Boddeke HW, Eggen BJ: In acute experimental autoimmune encephalomyelitis, infiltrating macrophages are immune activated, whereas microglia remain immune suppressed. Glia 2014, 62:1724-1735.

5. Mahad DH, Trapp BD, Lassmann H: Pathological mechanisms in progressive multiple sclerosis. The Lancet Neurology 2015, 14:183-193.

6. Fourgeaud L, Traves PG, Tufail Y, Leal-Bailey H, Lew ED, Burrola PG, Callaway P, Zagorska A, Rothlin CV, Nimmerjahn A, Lemke G: TAM receptors regulate multiple features of microglial physiology. Nature 2016, 532:240-244.

7. Miron VE, Boyd A, Zhao JW, Yuen TJ, Ruckh JM, Shadrach JL, van Wijngaarden P, Wagers AJ, Williams A, Franklin RJM, Ffrench-Constant C: M2 microglia and macrophages drive oligodendrocyte differentiation during CNS remyelination. Nat Neurosci 2013, 16:1211-1218.

8. Lastwika KJ, Wilson W, 3rd, Li QK, Norris J, Xu H, Ghazarian SR, Kitagawa H, Kawabata S, Taube JM, Yao S, et al: Control of PD-L1 Expression by Oncogenic Activation of the AKT-mTOR Pathway in NonSmall Cell Lung Cancer. Cancer Res 2016, 76:227-238.

9. Jack C, Ruffini F, Bar-Or A, Antel JP: Microglia and multiple sclerosis. J Neurosci Res 2005, 81:363373.

10. Shafit-Zagardo B, Gruber RC, DuBois JC: The role of TAM family receptors and ligands in the nervous system: From development to pathobiology. Pharmacol Ther 2018, 188:97-117.

11. Lemke G, Rothlin CV: Immunobiology of the TAM receptors. Nat Rev Immunol 2008, 8:327-336.

12. Lemke G, Burstyn-Cohen T: TAM receptors and the clearance of apoptotic cells. Ann N Y Acad Sci 2010, 1209:23-29.

13. Korshunov VA: Axl-dependent signalling: a clinical update. Clin Sci (Lond) 2012, 122:361-368.

14. Orme JJ, Du Y, Vanarsa K, Mayeux J, Li L, Mutwally A, Arriens C, Min S, Hutcheson J, Davis LS, et al: Heightened cleavage of Axl receptor tyrosine kinase by ADAM metalloproteases may contribute to disease pathogenesis in SLE. Clin Immunol 2016, 169:58-68.

15. Li N, Liu Z, Zhang Y, Chen Q, Liu P, Cheng CY, Lee WM, Chen Y, Han D: Mice lacking Axl and Mer tyrosine kinase receptors are susceptible to experimental autoimmune orchitis induction. Immunol Cell Biol 2015, 93:311-320.

16. Weinger JG, Brosnan CF, Loudig O, Goldberg MF, Macian F, Arnett HA, Prieto AL, Tsiperson V, ShafitZagardo B: Loss of the receptor tyrosine kinase Axl leads to enhanced inflammation in the CNS and delayed removal of myelin debris during Experimental Autoimmune Encephalomyelitis. Journal of Neuroinflammation 2011, 8:49. 
17. Tsukita Y, Fujino N, Miyauchi E, Saito R, Fujishima F, Itakura K, Kyogoku Y, Okutomo K, Yamada M, Okazaki T, et al: Axl kinase drives immune checkpoint and chemokine signalling pathways in lung adenocarcinomas. Mol Cancer 2019, 18:24.

18. Latchman YE, Liang SC, Wu Y, Chernova T, Sobel RA, Klemm M, Kuchroo VK, Freeman GJ, Sharpe AH: PD-L1-deficient mice show that PD-L1 on T cells, antigen-presenting cells, and host tissues negatively regulates T cells. Proc Natl Acad Sci U S A 2004, 101:10691-10696.

19. Hu J, He H, Yang Z, Zhu G, Kang L, Jing X, Lu H, Song W, Bai B, Tang H: Programmed Death Ligand-1 on Microglia Regulates Th1 Differentiation via Nitric Oxide in Experimental Autoimmune Encephalomyelitis. Neurosci Bull 2016, 32:70-82.

20. Francisco LM, Salinas VH, Brown KE, Vanguri VK, Freeman GJ, Kuchroo VK, Sharpe AH: PD-L1 regulates the development, maintenance, and function of induced regulatory $\mathrm{T}$ cells. $J$ Exp Med 2009, 206:3015-3029.

21. Zhang H, Guo M, Zhang L, Xue H, Chai Z, Yan Y, Xing Y, Xiao B, Zhang P, Ma C: [Anti-inflammatory effect and mechanisms of Huangqi glycoprotein in treating experimental autoimmune encephalomyelitis]. Folia Neuropathol 2017, 55:308-316.

22. Rothlin CV, Ghosh S, Zuniga El, Oldstone MB, Lemke G: TAM receptors are pleiotropic inhibitors of the innate immune response. Cel/ 2007, 131:1124-1136.

23. Ho WE, Peh HY, Chan TK, Wong WS: Artemisinins: pharmacological actions beyond anti-malarial. Pharmacol Ther 2014, 142:126-139.

24. Guo Z: Artemisinin anti-malarial drugs in China. Acta Pharm Sin B 2016, 6:115-124.

25. Li X, Li TT, Zhang XH, Hou LF, Yang XQ, Zhu FH, Tang W, Zuo JP: Artemisinin analogue SM934 ameliorates murine experimental autoimmune encephalomyelitis through enhancing the expansion and functions of regulatory T cell. PLOS One 2013, 8:e74108.

26. Liu J, Hong X, Lin D, Luo X, Zhu M, Mo H: Artesunate influences Th17/Treg lymphocyte balance by modulating Treg apoptosis and Th17 proliferation in a murine model of rheumatoid arthritis. Exp Ther Med 2017, 13:2267-2273.

27. Noori S, Hassan ZM: Dihydroartemisinin shift the immune response towards Th1, inhibit the tumor growth in vitro and in vivo. Cell Immunol 2011, 271:67-72.

28. Zhao YG, Wang Y, Guo Z, Gu AD, Dan HC, Baldwin AS, Hao W, Wan YY: Dihydroartemisinin ameliorates inflammatory disease by its reciprocal effects on Th and regulatory $\mathrm{T}$ cell function via modulating the mammalian target of rapamycin pathway. $J$ Immunol 2012, 189:4417-4425.

29. Li S, Shi Z, Zhang H, Liu X, Chen S, Jin J, Wang Y, Jia W, Li H: Assessing gait impairment after permanent middle cerebral artery occlusion in rats using an automated computer-aided control system. Behav Brain Res 2013, 250:174-191.

30. McArthur S, Cristante E, Paterno M, Christian H, Roncaroli F, Gillies GE, Solito E: Annexin A1: a central player in the anti-inflammatory and neuroprotective role of microglia. J Immunol 2010, 185:63176328. 
31. Petti AA, Williams SR, Miller CA, Fiddes IT, Srivatsan SN, Chen DY, Fronick CC, Fulton RS, Church DM, Ley TJ: A general approach for detecting expressed mutations in AML cells using single cell RNAsequencing. Nat Commun 2019, 10:3660.

32. Nishijima H, Kajimoto T, Matsuoka Y, Mouri Y, Morimoto J, Matsumoto M, Kawano H, Nishioka Y, Uehara $\mathrm{H}$, Izumi K, et al: Paradoxical development of polymyositis-like autoimmunity through augmented expression of autoimmune regulator (AIRE). J Autoimmun 2018, 86:75-92.

33. Voet S, Prinz M, van Loo G: Microglia in Central Nervous System Inflammation and Multiple Sclerosis Pathology. Trends Mol Med 2019, 25:112-123.

34. Carter LL, Leach MW, Azoitei ML, Cui J, Pelker JW, Jussif J, Benoit S, Ireland G, Luxenberg D, Askew GR, et al: PD-1/PD-L1, but not PD-1/PD-L2, interactions regulate the severity of experimental autoimmune encephalomyelitis. J Neuroimmuno/ 2007, 182:124-134.

35. Zhang Q, Vignali DA: Co-stimulatory and Co-inhibitory Pathways in Autoimmunity. Immunity 2016, 44:1034-1051.

36. Cheng X, Zhao Z, Ventura E, Gran B, Shindler KS, Rostami A: The PD-1/PD-L pathway is up-regulated during IL-12-induced suppression of EAE mediated by IFN-gamma. J Neuroimmuno/ 2007, 185:7586.

37. Pittaluga A: CCL5-Glutamate Cross-Talk in Astrocyte-Neuron Communication in Multiple Sclerosis. Front Immunol 2017, 8:1079.

38. Martin-Blondel G, Brassat D, Bauer J, Lassmann H, Liblau RS: CCR5 blockade for neuroinflammatory diseases-beyond control of HIV. Nat Rev Neurol 2016, 12:95-105.

39. O'Loughlin E, Madore C, Lassmann H, Butovsky O: Microglial Phenotypes and Functions in Multiple Sclerosis. Cold Spring Harb Perspect Med 2018, 8.

40. Jiang W, Cen Y, Song Y, Li P, Qin R, Liu C, Zhao Y, Zheng J, Zhou H: Artesunate attenuated progression of atherosclerosis lesion formation alone or combined with rosuvastatin through inhibition of proinflammatory cytokines and pro-inflammatory chemokines. Phytomedicine 2016, 23:1259-1266.

41. Saijo K, Glass CK: Microglial cell origin and phenotypes in health and disease. Nat Rev Immunol 2011, 11:775-787.

42. Yamasaki R, Lu H, Butovsky O, Ohno N, Rietsch AM, Cialic R, Wu PM, Doykan CE, Lin J, Cotleur AC, et al: Differential roles of microglia and monocytes in the inflamed central nervous system. $J$ Exp Med 2014, 211:1533-1549.

43. Sage PT, Schildberg FA, Sobel RA, Kuchroo VK, Freeman GJ, Sharpe AH: Dendritic Cell PD-L1 Limits Autoimmunity and Follicular T Cell Differentiation and Function. J Immuno/ 2018, 200:2592-2602.

44. Haque A, Best SE, Amante FH, Mustafah S, Desbarrieres L, de Labastida F, Sparwasser T, Hill GR, Engwerda CR: CD4+ natural regulatory T cells prevent experimental cerebral malaria via CTLA-4 when expanded in vivo. PLoS Pathog 2010, 6:e1001221.

\section{Supplemental Information Note}


Graphical abstract Dihydroartemisinin (DHA), a Candidate for immunosuppression, could effectively promote PDL1 and T cells differentiate into Treg cells, but inhibit the CNS inflammation and chemotaxis by up-regulating AXL in microglia depending on amplification of phosphorylation STAT1 status and expression of SOCS3.

\section{Figures}

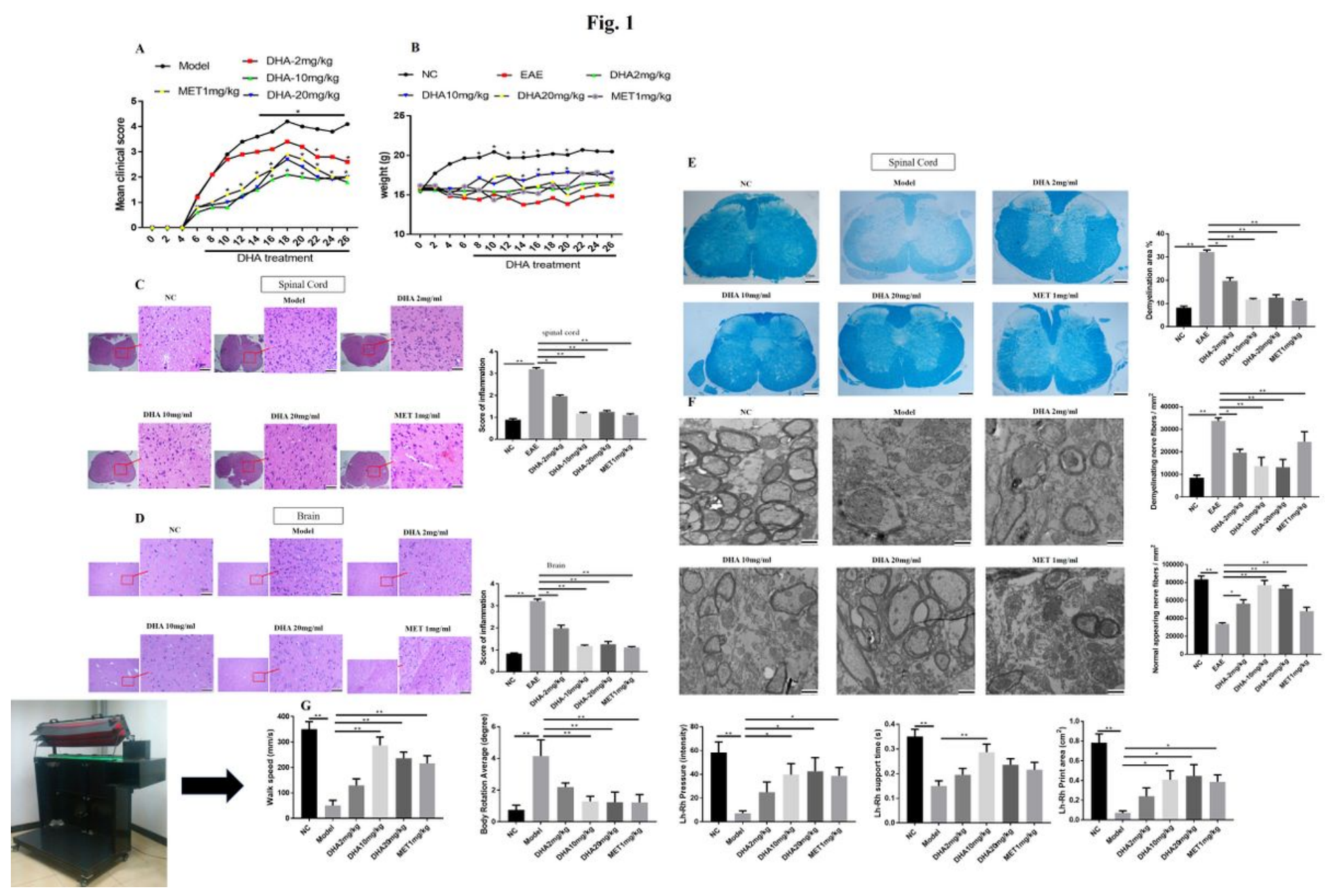

Figure 1

DHA treatment inhibited the development of EAE in MOG-immunized C57BL/6 mice A, B) Mean clinical scores and weight of EAE mice that were i.g. daily with $\operatorname{DHA}(2,10,20 \mathrm{mg} / \mathrm{kg}), \operatorname{MET}(1 \mathrm{mg} / \mathrm{kg})$ or vehicle control from day 7 ( $n=10$, preventive treatment) post immunization onwards. C, D, E) Transverse sections of brains spinal cords from control EAE mice and DHA-treated mice were stained with H\&E $(\times 40$ and $\times 100)$ or Luxol fast blue $(\times 40)$. Histopathology score of CNS inflammation and demyelination was quantified using $\mathrm{H} \& \mathrm{E}$ and Luxol fast blue staining on day 26 post immunization. F) TEM images ( $\times$ 15000) showed demyelinated axons in the spinal cords of control EAE, MET-treated and DHA-treated mice on day 26. G) Gait analysis (walk speed; Body Rotation Average; Lh-Rh Pressure; Lh-Rh support time; LhRh Print area) of control EAE, MET-treated and DHA-treated mice from day 20 to day 26. Data are 
representative of three independent experiments. ${ }^{*} \mathrm{P}=<0.05 ; * * \mathrm{P}=<0.01 . \mathrm{MET}=$ methylprednisolone; $\mathrm{Lh}=\mathrm{Left}$ hindpaw; Rh= Right hindpaw.

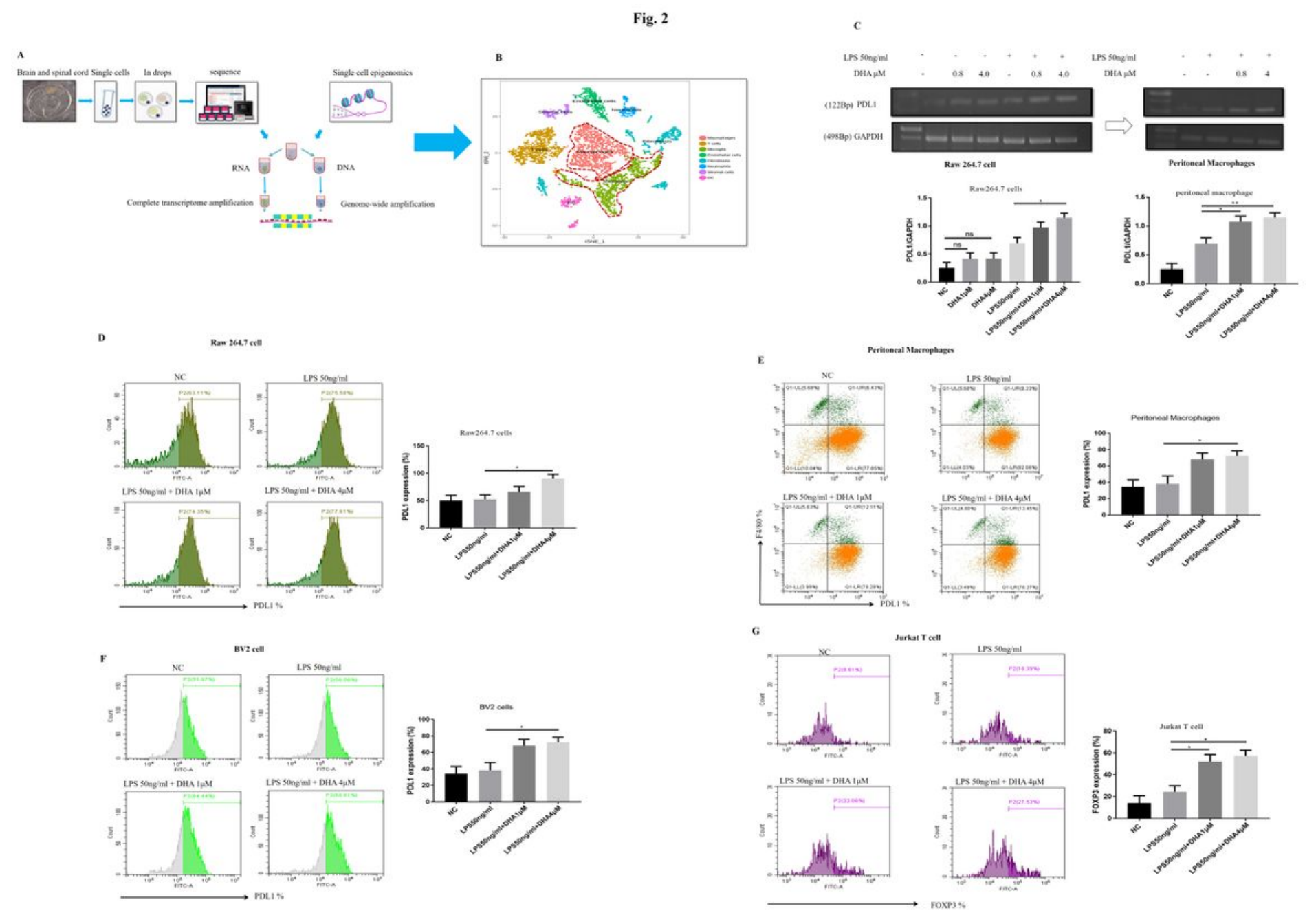

Figure 2

Macrophages and microglia are disease-responsive cells in EAE mice and DHA treatment promoted the differentiation of T cells into Treg cells by enhancing PDL1 expression in macrophages and microglia A) Flow chart of 10X Genomics single-cell assay by using the spinal cord and brain from EAE and DHA treated mice. B) the t-SNE projection of scRNA-seq data showed clusters of cells which would response to the disease in EAE mice. Peritoneal macrophages from C57BL/ 6 mice were challenged by $3 \%$ sodium thioglycolate three days in advance. C) RT-PCR analysis for PDL1 transcription in Raw 264.7 cells and peritoneal macrophages which were treated by LPS $(50 \mathrm{ng} / \mathrm{ml})$ and DHA $(1,4 \mu \mathrm{M})$. D, E, F) Flow cytometry assay for PDL1 expression in Raw 264.7 cells, peritoneal macrophages (PDL1+/F480+) and BV2 cells by LPS $(50 \mathrm{ng} / \mathrm{ml})$ and DHA $(1,4 \mu \mathrm{M})$ treatment. BV2 cells were treated by DHA $(1,4 \mu \mathrm{M})$ or LPS $(50 \mathrm{ng} / \mathrm{ml})$ for $12 \mathrm{~h}$, and then Jurkat T cells were co-cultured with BV2 cells for another 12h. G) FOXP3 expression on Jurkat $T$ cells analyzed by flow cytometry. Data are representative of three independent experiments. ${ }^{P}=$ $<0.05 ; * \star P=<0.01$. 

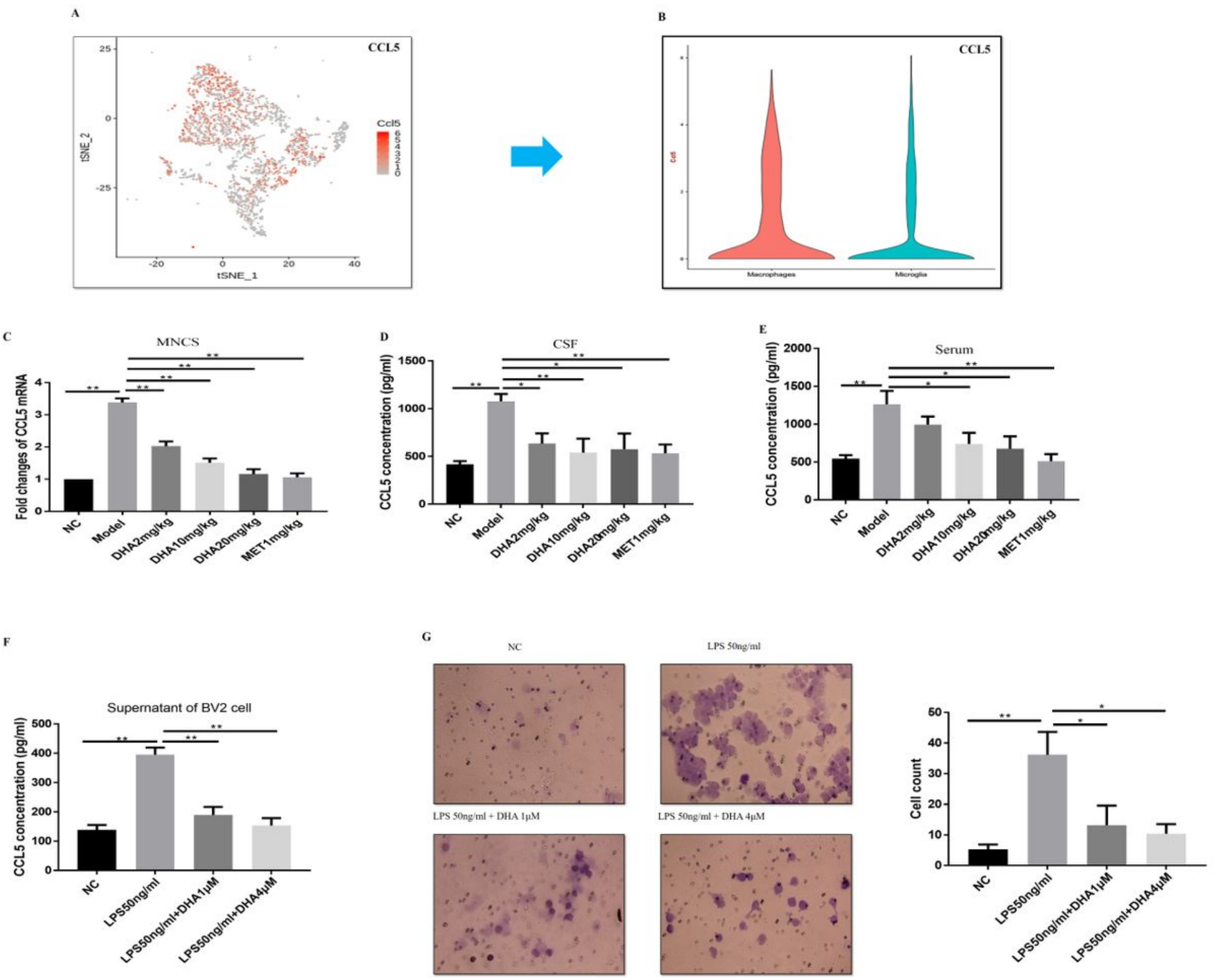

Figure 3

DHA treatment reduced the chemotactic ability of microglia by regulating CCL $5 \mathrm{~A}, \mathrm{~B}) \mathrm{CNV}$ analysis showed that CCL5 were almost expressed in macrophages and microglia (red, cells with detected CNVs; gray, no detected CNVs). MNCS from EAE, MET $(1 \mathrm{mg} / \mathrm{kg})$ and DHA $(2,10,20 \mathrm{mg} / \mathrm{kg})$ mice were harvested by $30 / 70 \%$ percoll gradient separation. C) qRT-PCR assay for CCL5 were analyzed by LightCycler 480 《 Roche. D, E) CSF and serum were obtained from EAE, MET $(1 \mathrm{mg} / \mathrm{kg})$ and $\operatorname{DHA}(2,10,20 \mathrm{mg} / \mathrm{kg})$ mice, ELISA assay for CCL5 analysis were carried out by using the CSF and serum. The supernatant of BV2 cells was harvested under the treatment of DHA $(1,4 \mu \mathrm{M})$ or LPS $(50 \mathrm{ng} / \mathrm{ml})$ for $12 \mathrm{~h}$, and transferred into 24-well plate for chemotaxis. F) Supernatant from BV2 cells that were treated with DHA $(1,4 \mu \mathrm{M})$ and LPS 
(50ng/ml). G) Chemotaxis ability of BV2 cells by using trans well assay. Data are representative of three independent experiments. ${ }^{*} \mathrm{P}=<0.05 ;{ }^{*} \mathrm{P}=<0.01$.

Fig. 4
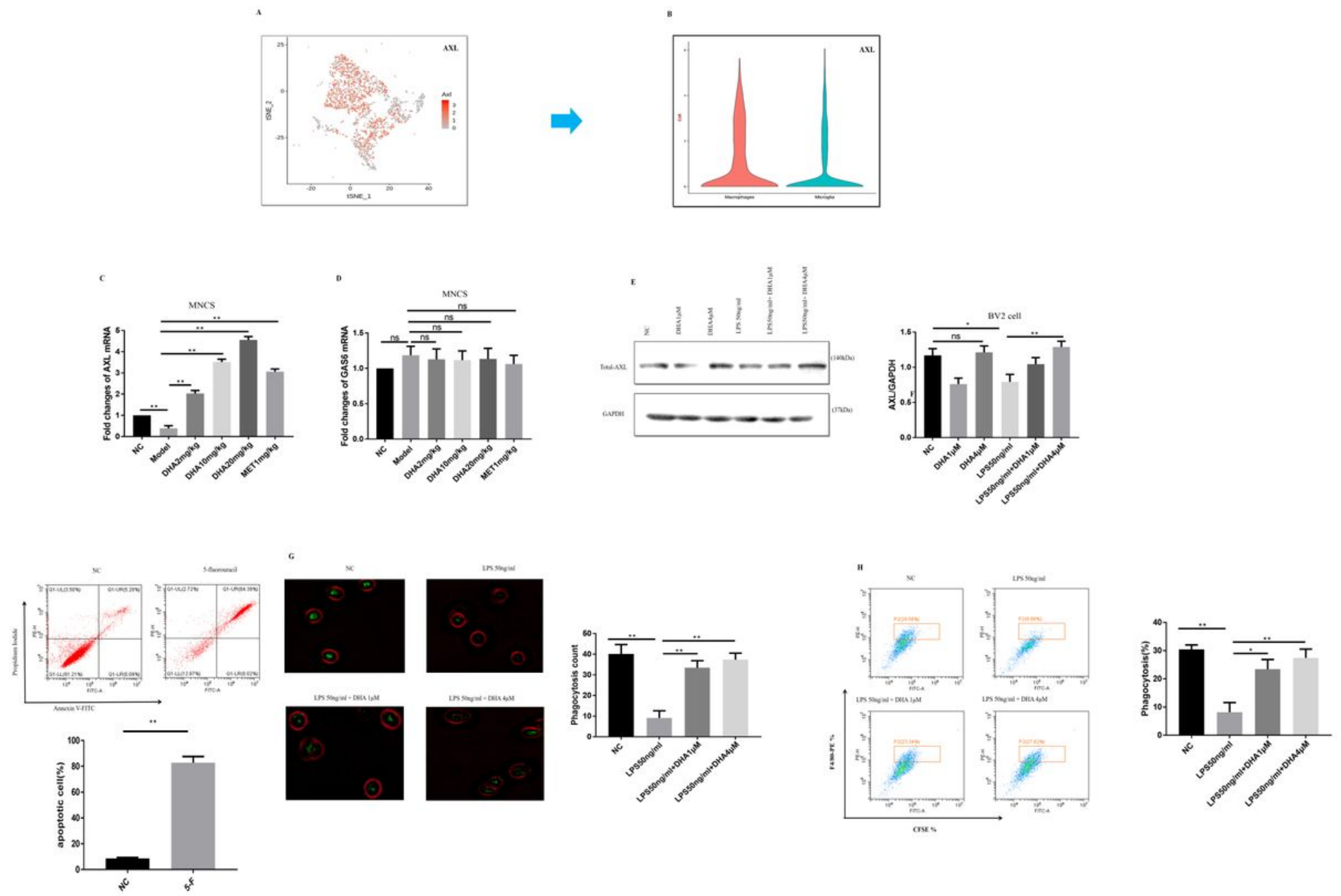

Figure 4

DHA treatment enhanced the phagocytic ability of microglia via up-regulating $A X L A, B) C N V$ analysis showed that $\mathrm{AXL}$ were almost expressed in macrophages and microglia (red, cells with detected CNVs; gray, no detected CNVs). MNCS from EAE, MET $(1 \mathrm{mg} / \mathrm{kg})$ and DHA $(2,10,20 \mathrm{mg} / \mathrm{kg})$ mice were harvested by $30 / 70 \%$ percoll gradient separation. C, D) qRT-PCR assay for AXL and GAS6 were analyzed by LightCycler $480 \otimes$ Roche. E) Western blot analysis for AXL expression in BV2 cells under the treatment of LPS $(5 \mathrm{ng} / \mathrm{ml})$ and DHA $(1,4 \mu \mathrm{M})$. F) We used $5-\mathrm{F}$ to induced the apoptosis of PC12 cells, AV-PI analysis showed the 5-F could induce the apoptosis of PC12 cells. PC12 cells were then transferred into BV2 cells for $2 \mathrm{~h} . \mathrm{G}, \mathrm{H}$ ) Fluorescence microscope images $(\times 400)$ showed count of phagocyting apoptosis cell by BV2 cells (green represent PC12 cells; red represent BV2 cells) and Flow cytometry assay showed the percent of phagocytosis cell (CYSE+/F480+). Data are representative of three independent experiments. ${ }^{*} \mathrm{P}=<0.05 ; * * \mathrm{P}=<0.01 .5-\mathrm{F}=5$-fluorouracil. 

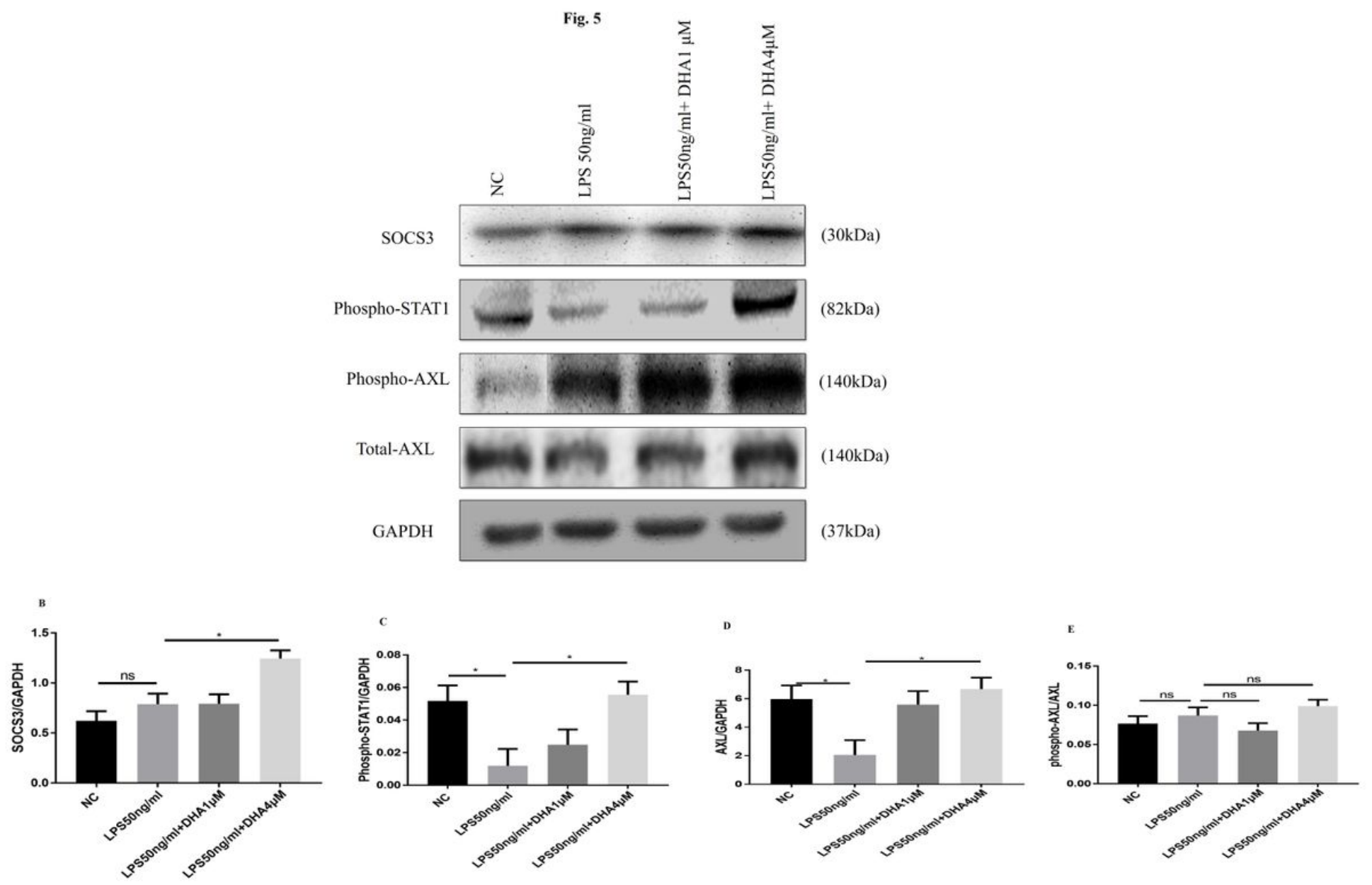

Figure 5

DHA treatment suppressed CNS inflammatory response via up-regulating AXL through STAT1/SOCS3 pathway BV2 cells were treated by DHA $(1,4 \mu \mathrm{M})$ or LPS $(50 \mathrm{ng} / \mathrm{ml})$ for $12 \mathrm{~h} . \mathrm{A}, \mathrm{B}, \mathrm{C}, \mathrm{D}, \mathrm{E})$ Cells were then analyzed for Phospho-STAT1; SOCS3; phospho-AXL and Total-AXL by Western blot. 


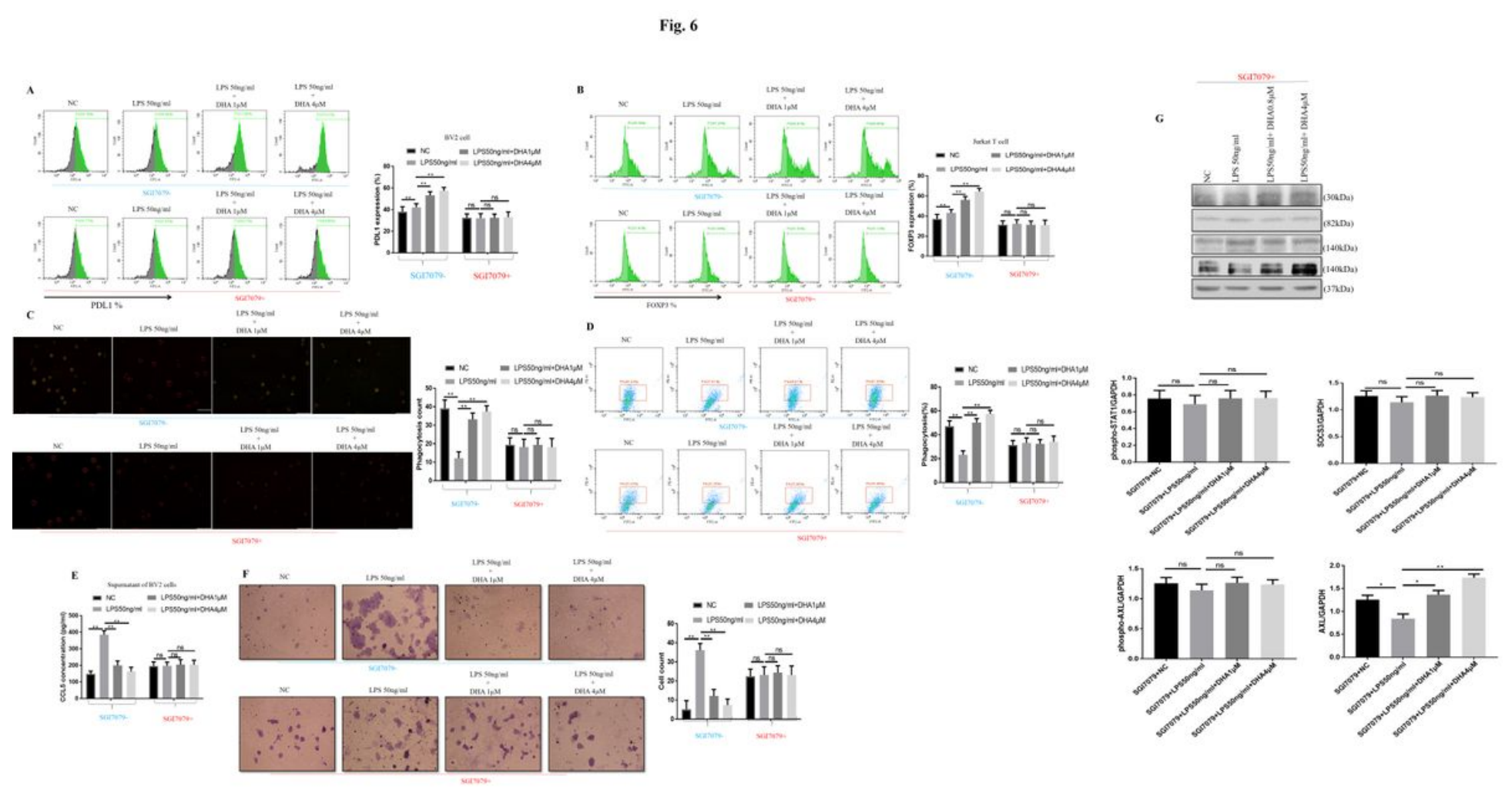

Figure 6

AXL is the potential target of DHA in CNS inflammatory niche BV2 cells treated by SGI7079 $(0.2 \mu \mathrm{M}), \mathrm{DHA}$ $(1,4 \mu \mathrm{M})$ or LPS $(50 \mathrm{ng} / \mathrm{ml})$ for $12 \mathrm{~h}$, and then Jurkat T cells were co-cultured with BV2 cells for another 12h. A, B) Flow cytometry showed PDL1 expression on and FOXP3 expression on Jurkat T cells. PC12 cells were induced by apoptosis by $5-\mathrm{F}$ and then transferred into BV2 cells for $2 \mathrm{~h}$. C, D) Fluorescence microscope images $(\times 400)$ showed count of phagocytosis cell by BV2 cells and Flow cytometry assay showed the percent of phagocyting apoptosis cell ( $\mathrm{CYSE}+/ \mathrm{F} 480+$ ) under the treatment of SGI7079 $(0.2 \mu \mathrm{M})$, DHA $(1,4 \mu \mathrm{M})$ or LPS $(50 \mathrm{ng} / \mathrm{ml})$. The supernatant of BV2 cells was harvested under the treatment of SGI7079 $(0.2 \mu \mathrm{M})$, DHA $(1,4 \mu \mathrm{M})$ or LPS $(50 \mathrm{ng} / \mathrm{ml})$ for $12 \mathrm{~h}$, and transferred into 24-well plate for chemotaxis. E, F) ELISA assay and trans-well assay showed the influence of CCL5 expression treated by SGI7079. BV2 cells were treated by SGI7079 $(0.2 \mu \mathrm{M})$, DHA $(1,4 \mu \mathrm{M})$ or LPS $(50 \mathrm{ng} / \mathrm{ml})$ for $12 \mathrm{~h}$. G) Cells were then analyzed for Phospho-STAT1; SOCS3; phospho-AXL and Total-AXL by Western blot. Data are representative of three independent experiments. ${ }^{*} \mathrm{P}=<0.05 ;{ }^{*} \mathrm{P}=<0.01$. 

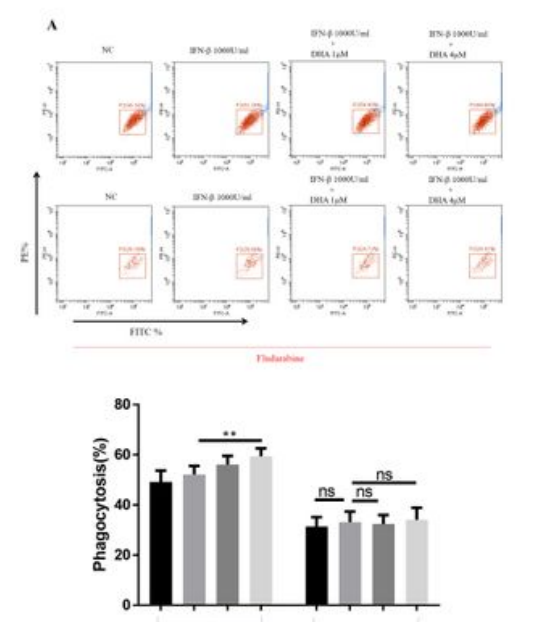

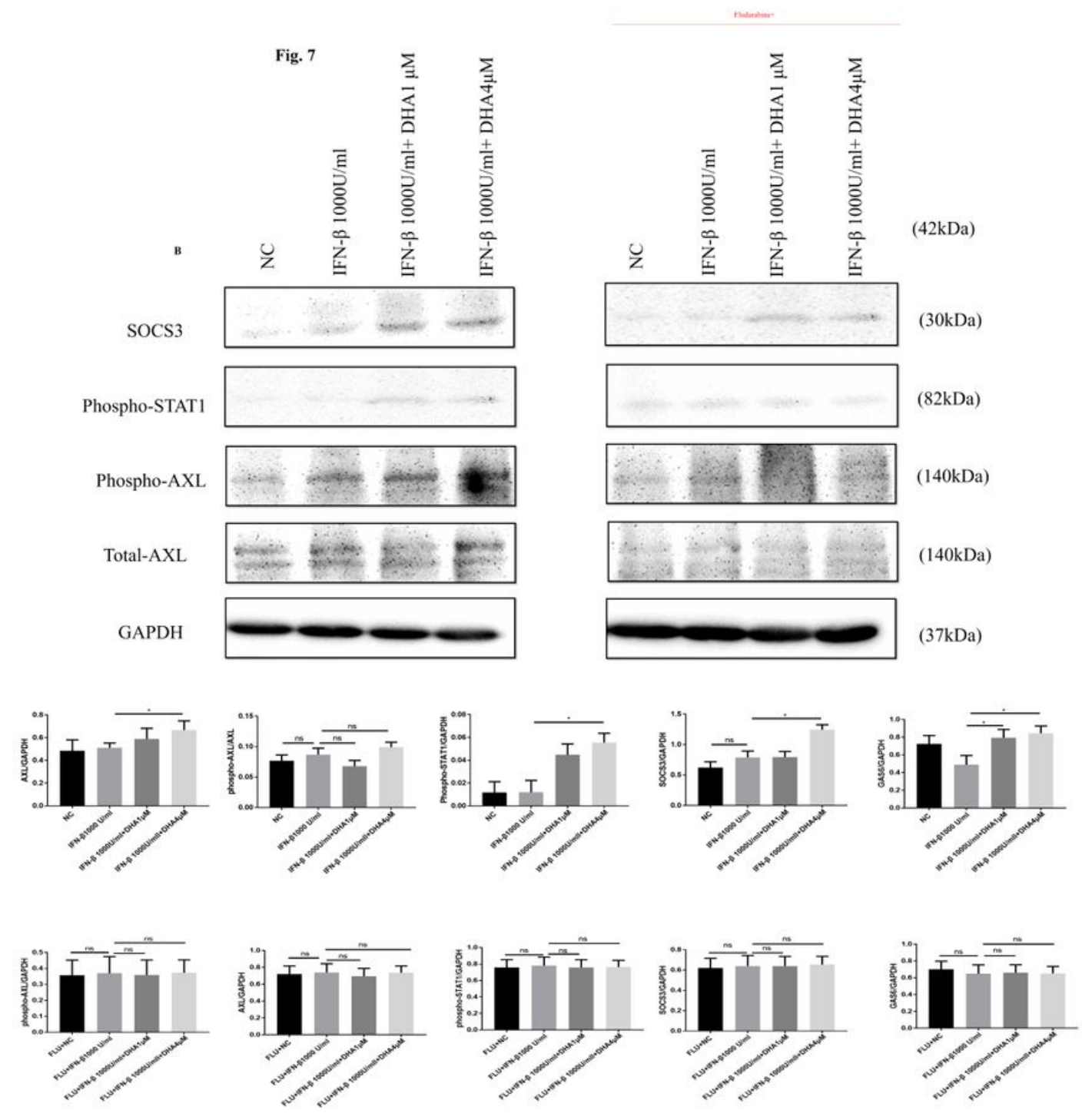

Figure 7

DHA inhibition of inflammation in CNS is dependent on the presence of the type I IFN receptor BV2 cells were treated by DHA $(1,4 \mu \mathrm{M})$ for $24 \mathrm{~h}$, Fludarabine $(0.25 \mu \mathrm{M})$ for, or IFN- $\beta(1000 \mathrm{U} / \mathrm{ml})$ for $12 \mathrm{~h}$. A) Flow cytometry assay showed the percent of phagocyting apoptosis cell ( $\mathrm{CYSE}+/ \mathrm{F} 480+)$. B) Cells were then analyzed for Phospho-STAT1; SOCS3; phospho-AXL and Total-AXL by Western blot. Data are representative of three independent experiments. ${ }^{*} P=<0.05 ; * \star P=<0.01$.

\section{Supplementary Files}

This is a list of supplementary files associated with this preprint. Click to download.

- Fig.8.jpg 